\title{
Studi Kelayakan Ekonomis Rencana Pembangunan Pelabuhan Sungai Liong Desa Berancah Kabupaten Bengkalis
}

\author{
Nur Rahmani, Akmal Lazuardy \\ Politeknik Negeri Bengkalis, Jl. Bathin Alam, Bnegkalis, Riau ${ }^{1}$ \\ Correspondence e-mail : $\underline{\text { nurrahmani11@polbeng.ac.id }}^{1}$, $\underline{\text { akmal.lazuardy@polbeng.ac.id }}^{2}$
}

\begin{abstract}
The fish shelter port (TPI) is a need that needs to be prepared by local village officials and the government for every coastal village in Bengkalis Regency. This research was conducted in the Berancah village of Bantan District. The analysis in this study describes the economic feasibility mathematically for the construction of a fish storage port (TPI) by calculating the cost ratio (B / C ratio) benefit analysis, payback period $(P P)$, net present value (NPV), and internal rate of return (IRR). The results obtained from the NPV value (3,661,267,645), BCR value (0.943), IRR value of $10.01 \%$, and PP are in the period of 30 years. Taken as a whole by standardizing the calculations, it can be concluded that the planned construction of a fish shelter in Berancah village is considered not economically feasible, but economic analysis is not merely a benchmark for feasibility, reviewed for the future many benefits will be received by the community around the location of the development plan so that it can improve the welfare of the community in Berancah village.
\end{abstract}

Keywords : Economic Feasibilit; Fish Shelte; Port

\section{PENDAHULUAN}

Kabupaten bengkalis memiliki 8 kecamatan yang tersebar yaitu antara lain kecamatan Mandau, Pinggir, Bukit Batu, dan Siak Kecil berada di sisi daratan Pulau Sumatera. Kecamatan Bengkalis dan Bantan berada di kawasan Pulau Bengkalis. Sementara Kecamatan Rupat dan Rupat Utara berada di Pulau Rupat. Dengan total luas wilayah $7.773 \mathrm{~km}^{2}, 71,34 \%$ merupakan wilayah pesisir (Kornitaet al, 2009). Menurut Badan Pusat Statistik Kabupaten Bengkalis (2017), ada 2.972 rumah tangga yang bermata pencaharian sebagai nelayan perikanan tangkap laut. Nelayan di Kabupaten Bengkalis menggunakan kapal berukuran 3 hingga 6 gross tonnage (GT) dengan jenis alat tangkap jaring batu (bottom drift gill net) dan rawai (Rengiet $a l, 2010)$. Dua jenis alat ini digunakan untuk menangkap ikan kurau (Eleutheronema tetradatcylum) yang merupakan komoditas utama bernilai ekonomis tinggi.

Produksi perikanan tangkap di Kabupaten Bengkalis mencapai 7.569 ton di tahun 2017.Hampir 38\% produksinya dihasilkan dari Pulau Bengkalis dengan Kecamatan Bantan berada di urutan kedua dari seluruh kecamatan dengan produktivitas 1.626 ton (BPS, 2017). Hal ini ditunjang dengan adanya tiga Tempat Pendaratan Ikan (TPI) yang berada di Kecamatan Bantan: TPI Selat Baru, TPI Teluk Pambang, dan TPI Bantan Air (Zain\& Syaifuddin, 2014). Dari ketiga TPI tersebut, hanya TPI Teluk Pambang yang dikelola koperasi, dua TPI lainnya dimiliki oleh swasta. Berdasarkan data Pusat Informasi Pelabuhan Perikanan tahun 2018 oleh Kemeterian Kelautan dan Perikanan menunjukkan bahwa Provinsi Riau hanya memiliki tiga pelabuhan perikanan saja, itu pun kelas D yaitu: Dumai, Tanjung Samak (Kabupaten Kepulauan Meranti), dan Sungai Guntung (Kabupaten Indragiri Hulu). Ketersediaan listrik, air bersih, tempat pelelangan ikan, bahan bakar, dan es merupakan fasilitas yang belum bisa dilengkapi oleh TPI yang ada di Kecamatan Bantan.

Sesuai Keputusan Menteri No. 10 Tahun 2014, untuk minimal menjadi pelabuhan perikanan kelas D, ada beberapa persyaratan teknis yang wajib dipenuhi seperti: (1) Melayani kapal perikanan di perairan pedalam dan kepulauan; (2) Memiliki fasilitas tambat labuh bagi kapal dengan ukuran minimal 3 GT; (3) Panjang drmaga minimal 50 meter dengan kedalaman kolam minimal 2 meter; (4) Mampu menampung minimal 20 kapal nelayan dengan total kapasitas dermaga maksimal 60 GT; dan (5) Memiliki lahan sekurang-kurangnya 2 hektar.

TPI yang ada di Kecamatan Bantan, TPI Bantan Air berpotensi untuk dikembangkan sebagai pelabuhan perikanan dengan ketentuan teknis seperti kelas D. TPI Bantan Air terletak di Sungai Liong, sekitar 60 menit dari ibukota kabupaten.Sungai Liong bermuara di Pantai Selat Baru dengan topologi landai dan menjorok hingga seratus meter ke arah laut. Penelitian ini memiliki tujuan (1) untuk mengetahui kondisi lokasi sebelum dan setelah pembangunan Pelabuhan Pendaratan Ikan Desa Berancah, (2) untuk mengetahui keadaan infrastruktur yang akan dibangun Tempat Pendaratan Ikan di Desa Berancah dan (3) untuk 
mengetahui perhitungan analisis kelayakan ekonomi dari perencanaan pembangunan Tempat Pendaratan Ikan di Desa Berancah

\section{METODE PENELITIAN}

Secara umum, tahapan peneltian ini terdiri dari beberapa langkah, yakni:

1. Studi Kelayakan Ekonomis, pada tahap ini mulai dilakukan perhitungan analisis kelayakan ekonomis pembangunan Pelabuhan TPI dengan beberapa metode penilaian kelayakan antara lain: 1) Analisis Pendapatan Usaha, 2) Benefit Cost Ratio, 3) Payback Period, 4) Net Present Value, 5) Internal Rate of Return. Melakukan Perhitungan dan Membuat Laporan Perhitungan dengan metode Studi Kelayakan Ekonomis

2. Kesimpulan dan laporan, Tahapan terakhir adalah membuat kesimpulan dan memberikan rekomendasi kepada pihak di Desa Berancah mengenai kelayakan ekonomis pembangunan Pelabuhan TPI serta mengevaluasi serta memberikan saran yang dapat diberikan untuk pengembangan penelitian lebih lanjut.

\section{HASIL DAN PEMBAHASAN}

\section{Analisis Biaya Investasi}

Biaya investasi dalam penelitian ini terdiri dari biaya tanah dan biaya konstruksi, sehingga perhitungannya sebagai berikut :

Biaya tanah (land cost)

Biaya pengadaan lahan adalah $=4200 \mathrm{~m}^{2} \times \mathrm{Rp} 1.250 .000=\mathrm{Rp} 5.250 .000 .000$

Biaya konstruksi

Tabel 1.

Biaya Konstruksi

\begin{tabular}{|c|c|c|c|c|c|c|c|}
\hline \multirow{2}{*}{ No } & \multirow{2}{*}{ Uraian } & \multicolumn{3}{|c|}{ Satuan } & \multirow{2}{*}{ Volume } & \multirow{2}{*}{$\begin{array}{c}\text { Harga Satuan } \\
\text { ( Rp ) }\end{array}$} & \multirow{2}{*}{$\begin{array}{c}\text { Jumlah } \\
\text { ( Rp ) }\end{array}$} \\
\hline & & Panjang & Lebar & Luas & & & \\
\hline 1 & TPI & 2 & 20 & 30 & 1200 & Rp 3.000.000,00 & Rp 3.600.000.000,00 \\
\hline 2 & Kantor administrasi & 1 & 20 & 18 & 360 & $\operatorname{Rp} 3.000 .000,00$ & Rp 1.080.000.000,00 \\
\hline 3 & Penyimpanan BBM & 1 & 10 & 9 & 90 & Rp 3.000.000,00 & $\mathrm{Rp} \quad 270.000 .000,00$ \\
\hline 4 & Tandon air bersih & 1 & 7 & 9 & 63 & Rp 3.000.000,00 & $\operatorname{Rp} \quad 189.000 .000,00$ \\
\hline 5 & Gudang es & 1 & 10 & 9 & 90 & $\operatorname{Rp} 3.000 .000,00$ & $\operatorname{Rp} \quad 270.000 .000,00$ \\
\hline 6 & Kantin & 1 & 10 & 10 & 100 & $\operatorname{Rp} 3.000 .000,00$ & $\operatorname{Rp} \quad 300.000 .000,00$ \\
\hline 7 & Toilet & 1 & 10 & 10 & 100 & $\operatorname{Rp} 3.000 .000,00$ & $\operatorname{Rp} \quad 300.000 .000,00$ \\
\hline 8 & Gudang penyimpanan & 1 & 10 & 7 & 70 & Rp 3.000.000,00 & $\operatorname{Rp} \quad 210.000 .000,00$ \\
\hline 9 & Ruang genset & 1 & 10 & 8 & 80 & $\operatorname{Rp} 3.000 .000,00$ & $\operatorname{Rp} \quad 240.000 .000,00$ \\
\hline 10 & Tempat parkir & 1 & 20 & 30 & 600 & $\operatorname{Rp} \quad 500.000,00$ & $\mathrm{Rp} \quad 300.000 .000,00$ \\
\hline 11 & Dermaga & 1 & 50 & 6 & 300 & Rp 3.000.000,00 & $\operatorname{Rp} \quad 900.000 .000,00$ \\
\hline \multirow[t]{3}{*}{12} & Jalan & 1 & 60 & 6 & 360 & $\mathrm{Rp} \quad 500.000,00$ & $\operatorname{Rp} \quad 180.000 .000,00$ \\
\hline & \multirow{2}{*}{\multicolumn{5}{|c|}{$\begin{array}{l}\text { TOTAL } \\
\text { Persiapan dana dalam } 12 \text { tahap pembangunan }\end{array}$}} & & Rp 7.839.000.000,00 \\
\hline & & & & & & & Rp $\quad 653.250 .000,00$ \\
\hline
\end{tabular}

Perhitungan analisis biaya investasi, jumlah yang diperlukan untuk rencana pembangunan pelabuhan TPI didesa Berancah dengan dasar anggaran kegiatan pembangunan persatuan ruang bangunan Rp $3.000 .000 / \mathrm{m}^{2}$, maka jumlah investasi diperlukan sebesar $\mathrm{Rp}$ 7.839.000.000,00. Jumlah investasi persiapan dana untuk 12 tahap pembangunan dalam perbulan dikisarkan biaya sebesar Rp 653.250.000. Maka total biaya langsung adalah penjumlahan biaya tanah dan biaya konstruksi ( Rp 5.250.000.000 + Rp 7.839.000.000 = Rp 13.089.000.000).

\section{Perhitungan Pendapatan Usaha}


Tabel 2

Asumsi Perhitungan Pendapatan Usaha

\begin{tabular}{lr}
\hline Asumsi perhitungan & 10 tahun \\
\hline Jangka waktu investasi & 30 tahun \\
Umur ekonomis bangunan & $12 \%$ \\
Suku bunga pinjaman & $12 \%$ \\
Suku bunga modal & $70 \%: 30 \%$ \\
Perbandingan pinjaman dan modal & Cost of Capital $(\mathrm{COC})=(0,08 \times 0,70)+(0,12 \times 0,30)=9 \%$ \\
\hline
\end{tabular}

Sumber: Data Primer

Tabel 3

Perhitungan Biaya Kapital Pendapatan Usaha

\section{Tanah}

Luas area pelabuhan

Beli tanah

TOTAL BIAYA KAPITAL

Biaya operasional dan pemeliharaan (20\%)

Biaya bunga (12\%)

Biaya bunga modal sendiri (30\%)

Biaya bunga modal pinjaman (70\%)

Anuitas pengembalian modal sendiri (12\% selama 10 tahun)

Anuitas pengembalian modal pinjaman (12\% selama 10 tahun)

Amortisasi

Biaya depresiasi $(\mathrm{i}=12 \%, \mathrm{n}=30)$

Pajak

Pajak selama pelunasan $(\mathrm{n}=10)$

Pajak selama umur ekonomis $(n=30)$

TOTAL PENGELUARAN selama pembayaran

TOTAL PENGELUARAN setelah pelunasan

$\begin{array}{rr}1,250,000 & \text { per meter persegi } \\ 60 \times 70 & \text { meter } \\ 4,200 & \text { meter persegi }\end{array}$

$5,250,000,000$

rupiah

$13,089,000,000$

rupiah

$2,617,800,000 \quad$ rupiah

$1,570,680,000 \quad$ rupiah

471,204,000 rupiah

1,099,476,000 rupiah

694,963,717 per tahun

$1,621,582,007 \quad$ per tahun

2,316,545,725 per tahun

$973,162,132 \quad$ rupiah per tahun

$320,899,477$

$583,083,859$

$7,478,187,856$

$7,799,087,334$

Sumber: Data Primer

Dapat dihitung jumlah Pinjaman $70 \%$ sebesar Rp 9.162.300.000 sedangkan jumlah besaran rupiah untuk modal 30\% sebesar Rp 3.926.700.000 pinjaman dan modal

Tabel 4

Perhitungan NPV, BCR, IRR, Payback Period

\begin{tabular}{|c|c|c|c|c|c|}
\hline & NPV & & PV Konversi & & PV $8 \%$ \\
\hline Biaya investasi & $13,089,000,000$ & tahun 0 saja & $(13,089,000,000)$ & & $(13,089,000,000)$ \\
\hline Biaya operasional & $2,617,800,000$ & per tahun & $(21,086,860,591)$ & & $(29,470,625,236)$ \\
\hline $\begin{array}{l}\text { Total pengeluaran } \\
\text { peminjaman }\end{array}$ & $3,041,957,485$ & per tahun & $(17,187,738,231)$ & & $(20,411,782,334)$ \\
\hline $\begin{array}{l}\text { Total pengeluaran } \\
\text { umur ekonomis }\end{array}$ & $1,556,245,990$ & per tahun & $(12,535,847,750)$ & & $(17,519,880,187)$ \\
\hline \multirow[t]{2}{*}{ Total pendapatan } & $7,478,187,856$ & per tahun & $60,238,178,927$ & & $84,187,818,685$ \\
\hline & & & $\begin{array}{r}(3,661,267,645) \\
(454,523,157)\end{array}$ & $\begin{array}{l}\text { tidak layak } \\
\text { anuitas }\end{array}$ & $3,696,530,928$ \\
\hline
\end{tabular}

BCR 


\begin{tabular}{llr}
-0.94270267 & tidak layak & $(7,357,798,574)$ \\
IRR & & 0.020 \\
$(7,357,798,574)$ & & $10.0096 \%$ \\
0.50240 & tidak layak karena $<12 \%$ & \\
0.02010 & & \\
$10.01 \%$ & tahun & \\
PAYBACK & & \\
\hline
\end{tabular}

Sumber: Data Primer

Hasil perhitungan NPV, BCR, IRR menunjukkan nilai kelayakan ekonomis yang tidak layak. Nilai NPV yang diperoleh dilhat dari keuntungan bernilai negative $(12,826,815,619)$, nilai BCR bernilai negatif 0.94270267 , nilai IRR 10,01\% yang lebih kecil dari 12\% sebagai batas dasar bunga Bank. Sedangkan untuk Payback period akan balik modal selama 30 tahun.

\section{SIMPULAN}

Analisis biaya manfaat, membuktikan pelabuhan tidak layak secara ekonomis. Hal ini untuk mengukur tingkat kelayakan pelabuhan yang dibandingkan dengan investasi yang telah dikeluarkan. Indikator yang dipakai adalah IRR bernilai kecil dari tingkat suku bunga bank, Payback Period berjangka waktu 30 tahun , NPV bernilai negatif dan BCR juga bernilai negative. Disarankan bahwa rencana pembangunan TPI Desa Berancah ini tidak layak untuk dibangun.

\section{DAFTAR PUSTAKA}

Badan Pusat Statistik Kabupaten Bengkalis. (2017). Kabupaten Bengkalis Dalam Angka. ISSN: 02153866Keputusan Menteri Kelautan dan Perikanan Nomor 10/MEN/2004 tentang pelabuhan perikanan. Jakarta. 2004.

Journal of Fisheries Resources Utilization Management and Technology Volume 3, Nomor 3, Tahun 2014, Hlm 200-207 Online di : http://www.ejournal-s1.undip.ac.id/index.php/jfrumt

Kornita, S.E., Yushar Yusuf, Anthony Mayes. (2009). Analisis Perdagangan Komoditas Perikanan Di Kecamatan Bantan Kabupaten Bengkalis. Jurnal Ekonomi 17(2) pp. 132-149

Ramli, M. \& Nur'aini.(2009). Kinerja Koperasi Perikanan Pantai Madani Dari Sisi Keuangan Kasus Koperasi di Teluk Pambang Bengkalis.Berkala Perikanan Terubuk 37(1) pp. 27-27

Rengi, P., Usman Muhammad Tang, Hamdan Alawi. (2010). Penentuan Potensi dan Tingkat Pemanfaatan Sumberdaya Perikanan di Perairan Bengkalis.Jurnal Teknobiologi (1)1 pp. 36-50

Studi Kelayakan Pengembangan Pelabuhan Celukan Bawang. I Wayan Redana Dan Ida Bagus Putu Adnyana. Jurnal Ilmiah Teknik Sipil Vol. 10, No. 1, Januari 2006

Undang-undang Republik Indonesia Nomor 31 Tahun 2004 tentang perikanan. Jakarta. 2004.

Zain, J \& Syaifuddin.(2014). Pengembangan Tempat Pendaratan Ikan di Kecamatan Bantan Kabupaten Bengkalis Provinsi Riau.Jurnal Perikanan dan Kelautan 19(2) pp. 62-70 